\title{
नृत्य निर्देशक श्री हरिदत्त कल्लाः लोक कला के संदर्भ में
}

RITU SHARMA

Research Scholar, Department of Music, University of Rajasthan, Jaipur

\section{सार संक्षेपिका}

अंतर्राष्ट्रीय ख्याति प्राप्त नृत्य निर्देशक पं. हरिदत्त कल्ला जयपुर कत्थक घराने के प्रमुख एवं वरिष्ठ कलाकारों में से है। पारिवारिक सांगीतिक परिवेश में आपकी प्रारंभिक संगीत शिक्षा हुई तथा इसके बाद आपने नृत्य की शिक्षा जयपुर घराने के कत्थक नृत्य गुरू पं. लक्ष्मी नारायण जी पंवार व पं. गिरधारी जी महाराज से विधिवत् ग्रहण की और इसके साथ ही भारतीय पारम्परिक लोकनत्य एवं उनकी संरचनाओं का विधिवत् प्रशिक्षण स्व. विख्यात नृत्यगुरू श्री भगवान दास वर्मा जी से प्राप्त किया एवं इनके सान्निध्य में लोकनत्य व बैले नृत्य की शिक्षा प्राप्त की। लोक कला के संदर्भ में पं. हरिदत्त कल्ला का मानना है कि लोक कला एक ऐसी कला है जिस पर किसी प्रकार का कोई बंधन नहीं होता। यह एक स्वतंत्र अभिव्यक्ति है। लोक कलाओं में नवीनीकरण जरूरी है अन्यथा ये कलाएँ एक जगह रहकर सड़ जायेंगी अर्थात् नष्ट हो जायेंगी। इसके लिए लोक कलाओं में बदलाव आना जरूरी है क्योकि परिवर्तन ही प्रकृति का नियम है पर इसकी जमीन खत्म नहीं होनी चाहिए, खुशबू खत्म नहीं होनी चाहिए।

बीज शब्द

हरिदत्त कल्ला, लोक कला, जयपुर घराना

\section{भूमिका}

मन की अतःकरण की सुन्दर प्रस्तुति ही कला है, कला उस क्षितिज की भाँति है, जिसका कोई छोर नहीं, इतनी विशाल, इतनी विस्तृत, अनेक विधाओं को अपने में समेटे हुये है, तभी तो कवि मन कह उठता है-

\section{साहित्य संगीत कला विहीन:}

साक्षात् पशुः पुच्छ विषाणहीनः।।

इस कला के माध्यम से ही कलाकार आत्मा से स्वज्निल विचारों को साकार रूप देता है।

लोक कला

लोक कला, जिस पर कोई बंधन नहीं। यह एक स्वतंत्र अभिव्यक्ति है, लोक शब्द का अभिप्राय है, एक उन्मुक्त मस्ती, तन्मयता तथा लयात्मक अंग संचालन यही लोकभावना है। जनसामान्य के बीच पनपी एवं विकसित लोक कलाओं ने विश्व के कोने-कोने में राजस्थान का गौरव और मान बढ़ाया है, इन लोक कलाओं में प्रमुख रूप से लोक गायन, नृत्य एवं वादन पड़गायन, कालबेलिया नृत्य, घूमर, चरी, बहरूपिया, मांड गायन, हेला ख्याल गायन, भपंग वादन इत्यादि प्रमुख रूप से हैं। साथ ही इन लोक कलाओं एवं कलाकारों की वजह से ही सम्पूर्ण विश्व फलक पर राजस्थान का नाम गौरवांवित है।

लोकनृत्य संरचना के विकास व निर्देशन में महत्वपूर्ण योगदान देने वाले नृत्य निर्देशक श्री हरिदत्त कल्ला जी का जन्म 12 मार्च 1940 को जोधपुर में हुआ। आपके पिता का नाम श्री बालकृष्ण 
कल्ला एवं माता का नाम श्रीमती कृष्णा कल्ला है। श्री हरिदत्त कल्ला को अल्प उम्र में ही कलाओं के प्रति विशेष आकर्षण था। कल्ला जी ने भारतीय शास्त्रीय नृत्य कथक की शिक्षा जयपुर घराने के कत्थक नृत्य गुरू पं. लक्ष्मी नारायण जी पंवार व पं. गिरधारी जी महाराज से विधिवत् ग्रहण की। इसके पश्चात् आपका रूझान नव संरचनाओं की ओर होने के कारण आपने लोकनृत्य के क्षेत्र में प्रवेश किया जहाँ पर आपने नृत्य गुरू भगवान दास वर्मा जी के सान्निध्य में रहकर लोकनृत्यों का गहन अध्ययन किया एवं आपकी दो दशक समर्पित कला जीवन साधना चिरमी, तेरहलाती, गरासिया व पारम्परिक लोकनृत्य थे, जिनको आज भी देश-विदेश में प्रशंसा प्राप्त है।

आपने राजस्थान की सांस्कृतिक धरोहर पारम्परिक लोकनृत्य घूमर को प्रोत्साहित करने के लिए जयपुर में 2000 छात्राओं व महिलाओं को नृत्य प्रशिक्षण देकर छोटी-चौपड़ से बड़ी-चौपड़ तक 65 घेरे से घूमर नृत्य का सफल प्रदर्शन किया। साथ ही आपने लोकनृत्य में कुछ नवीन परिवर्तन लाने हेतु एक 'ओरिएन्टल' शैली का प्रशिक्षण प्राप्त किया, जिसके माध्यम से आपने अनेक लोकनृत्यों में इस ओरिएन्टल शैली का प्रयोग कर राजस्थान की लोकनृत्य शैली को चर्मोत्कृष तक पहुँचाया। जिसका प्रभाव नवोदित व मूर्धन्य कलाकारों पर पड़ा एवं आपके द्वारा किए गए लोकनृत्यों में इस शेली के प्रयोग से, युवा तथा वरिष्ठ कलाकारों ने आपके द्वारा किए गए प्रयोगों की प्रशंसा की।

आपकी संगीतमयी यात्रा संगीत समाज के विद्यार्थियों के लिए प्रेरणादायक है। शोध छात्रा ने नृत्य निर्देशक श्री हरिदत्त कल्ला जी से 'लोक कला' के संदर्भ में कुछ प्रश्न किए जिनका उत्तर संगीत विद्यार्थियों के लिए बहुत उपयोगी व प्रेरणादायक है, उनका उल्लेख इस प्रकार है :

1. लोक कला के संदर्भ में नृत्य निर्देशक श्री हरिदत्त कल्ला जी आपका मानना है कि लोक कला एक ऐसी कला है जिस पर किसी प्रकार का कोई बंधन नहीं होता। यह एक स्वतंत्र अभिव्यक्ति है जिसमें मानव अपनी प्रकृति से जुड़ा और यह कृषि प्रधान देश का वो व्यक्तित्व है जिसने अपनी सामाजिक परम्पराओं व अपनी अभिव्यक्तियों को प्रकृति से जुड़े उन हवाओं को आत्मसात् करते हुये अपने भावों को कला के माध्यम से उजागर किया है जिसे हम लोक कला कहते हैं और इनमें इनकी परम्पराओं से जुड़े आध्यात्मिक स्वरूप के रंग, इनके संगीत में, गायन में एवम् नृत्य में परिभाषित होते हैं और इन्हीं रंगों का हम आनंद लेते हैं।

आप राजस्थान की पृष्ठभूमि पर हर उस एक किनारे से परिचित हैं जहाँ ये कलाएँ प्रस्फुटित होती है, उदाहरण स्वरूप जैसलमेर के सुनहरी बालू मिट्टी के उन धोरों पर जब एक लम्बी कतार में ऊँटों पर सुशोभित ग्रामीण परिवेश में मोर चंग बजाते हुए रात के सन्नाटे में जब चलते हैं तो चारों ओर स्वर लहरियां सागर की लहरों के समान बिखरती व सुनाई देती है, 
और ऐसे प्रकृति भी इन स्वर लहरों में झूम उठती है। लोक कलाएँ देखने या सुनने से ज्यादा महसूस करने की वस्तु है और यही हमारी आत्मिक शक्ति है।

2. लोक कलाओं के संरक्षण तथा संवर्द्धन हेतु सरकार के द्वारा किए जा रहे प्रयास हेतु कल्ला जी बताते हैं कि भारत सरकार ने काफी कार्य किया है और कर रही है एवम् आगे भी करती रहेगी। इसमें भारत के हर भाग में सांस्कृतिक सांस्कृतिक केन्द्र खोल गए हैं जिनका कार्य अपने-अपने क्षेत्र के लोक कलाओं को उजागर करने के लिए एवम् उनको प्रोत्साहित करने के लिए, पारम्परिक लोक कलाकारों का चयन करके भारत के हर कोने में भेजना है जहाँ उनका पारम्परिक लोकनृत्य, लोक गायन, लोक कलाएँ, पारम्परिक वेशभूषा, पारम्परिक आध्यात्मिक स्वरूप के रंग, इनके प्रदर्शन में निर्धारित होती है। उदाहरण स्वरूप जवाहर कला केन्द्र, जयपुर में लोकरंग के नाम से एक बहुत बड़ा आयोजन होता था जिसमें प्रादेशिक लोकनृत्य, प्रादेशिक लोक गायन एवम् त्यौहारों के आधार पर रची बसी पारम्परिक लोक कलाओं का जवाहर कला केन्द्र के मध्यवर्ती मंच पर 11 दिन तक लगातार प्रदर्शन होता था। यह कार्यक्रम अंतर्राष्ट्रीय स्तर पर लोकरंग कार्यक्रम के नाम से अपनी पहचान बना चुका था क्योंकि विभिन्न प्रदेशों के विभिन्न लोक कलाओं का प्रदर्शन जिसने लोकनृत्य, गायन, वादन, लोकनाट्य इत्यादि का प्रदर्शन एक ही मंच पर जनता को देखने को मिलता था ये बहुत मुश्किल है कि विभिन्न प्रदेशों के लोकनृत्य, लोक कलाओं का प्रदर्शन एक ही मंच पर देखने को मिले। इसी तरह भारत के अनेकों जो कल्चर सेंटर बने हुये हैं वे अपनी-अपनी प्रदेश की कलाओं का वार्षिक प्रदर्शन तो करते ही हैं जिससे लोक कलाओं को पारिश्रमिक भी मिलता है एवम् राज्य सरकार की तरफ से यात्रा भत्ता व भोजन की व्यवस्था मिलता है, जिससे कलाकार को अपनी कलाओं को स्थापित करने का मौका मिलता है और वे अग्रसर होकर अपनी कलाओं को बढ़ाते रहते हैं।

3 लोक कलाकारों के व्यवसायिक होने के संदर्भ में कल्ला जी कहते हैं कि जाहिर सी बात है समय बदलता जा रहा है वे लोक कलाकार जो अपनी स्वतंत्र अभिव्यक्ति को उजागर करते थे वे अब पूर्ण रूप से व्यवसायिक हो गए हैं और साथ ही अपनी लोक कलाओं में गायन, वादन व अंग संचालन में नवीनता लाने हेतु एक दूसरे की कॉपी करने लगे हैं क्योंकि इनको प्रदर्शन का उचित पारिश्रमिक मिलने लगा है इस कारण से इन लोगों की मूल प्रवृति भी परम्पराओं के अनुसार विलुप्त होती जा रही है।

4. कलाकार के लिए रियाज जरूरत के विषय में कल्ला जी का मानना है कि रियाज जरूरी है चाहे लोक कलाकार हो, चाहे शास्त्रीय गायन का कलाकार हो या शास्त्रीय नृत्य का कलाकार हो क्योकि हर कला को निखारने के लिए रियाज बहुत जरूरी है। इसके लिए एक कलाकार 
को अपनी कला को प्राप्त करने हेतु सिद्धहस्त गुरू का चयन करना जरूरी है और उसे सीखने के लिए अपने आपको गुरू के प्रति अनुशासन में रहकर खूब तपस्या (रियाज) करना चाहिए। ताकि कला में खूबसूरती पैदा हो। एक अच्छे कलाकार को मुख्य रूप से मूलभूत तीन बातों को ध्यान में रखकर ही रियाज करना चाहिए -

(क) एकाग्रचित होना

(ख) ग्रहण करना

(ग) अपनी कल्पना को साकार रूप देना

इसको सरल शब्दों में कहना चाहेंगे तो वह है - देखो, सीखो और परखो। इन सभी बुनियादी बातों को ध्यान में रखकर ही रियाज करना चाहिए क्योंकि जितना हम कला को अपनाकर उसकी बारीकियों को समझकर उसका रियाज करेंगे उतनी ही वह कला चमक उठेगी।

5. लोक कलाओं के नवीनीकरण के बारे में कल्ला जी कहते हैं कि लोक कलाओं में नवीनीकरण जरूरी है अन्यथा ये कलाएँ एक जगह रहकर सड़ जायेंगी अर्थात् नष्ट हो जायेंगी। इसके लिए लोक कलाओं में बदलाव आना जरूरी है क्योकि परिवर्तन ही प्रकृति का नियम है पर इसकी जमीन खत्म नहीं होनी चाहिए, खुशबू खत्म नहीं होनी चाहिए। बदलाव के अनुरूप सबकुछ बदलता है, परम्पराओं को जिंदा रखने के लिए हमें परम्पराओं को ढोना पड़ेगा अन्यथा ये कलाएँ सीमित दायरे में आकर खत्म हो जायेगी क्योंकि आज के युग में नवीनीकरण होना बहुत जरूरी है और इस नवीनीकरण को आत्मसात् करने के लिए परम्पराओं को ध्यान में रखते हुए नवीनीकरण करना चाहिए।

6. लोक कलाओं के संरक्षण के लिए सरकार को और क्या करना चाहिए, इस संदर्भ में आप कहते हैं कि लोक कलाओं में हमें संस्कृति के दर्शन होते हैं और इन कलाओं को लुप्त होने से रोका नहीं गया तो हम संस्कृति को भी खोने से नहीं रोक सकते। इसलिए इन कलाओं का संरक्षण सरकारी स्तर पर इन कलाकारों को रोजगार देकर, इन कलाओं के वृतचित्र बनाकर एवम् इन विधाओं के कलाकारों की मंचीय प्रस्तुति करने के अवसर ज्यादा प्रदान करके, किया जाये जिससे इन कलाओं को ओर अधिक विकसित व निखारा जा सके।

इसके अतिरिक्त इन लोक विधाओं को शिक्षा के पाठ्यक्रम में भी शामिल किया जाए जिससे आने वाली युवा पीढ़ी इससे अवगत हो सके एवम् विभिन्न मंचीय प्रस्तुतियों में इन विधाओं के कलाकारों का मंच प्रदर्शन कराया जाये तो सम्भवतः जन सामान्य में यह कला फिर से विकसित हो सकती है। 
इसी के साथ सरकार को पारम्परिक मूल कला को बचाने के लिए उन्हीं कलाकारों का प्रदर्शन करवाना चाहिए जो अपनी परम्परा एवम् अपनी लोक कलाओं को नि:ख्वार्थ भावना से कला के स्वरूप को बनाये हुए है अन्यथा आने वाली पीढ़ी पारम्परिक लोकनृत्य एवम् गायन की विविध शैलियों को देखने से वंचित रहेगी और ये लोक कलाएँ विलुप्त हो जायेगी साथ ही इनकी जगह व्यवसायिक लोकनृत्य एवम् 'फ्यूजन' ले लेंगे और लोकनृत्य के नाम से अनेक लोकनृत्य का प्रभाव उसमें दिखाई देगा और वे नवीन लोकनृत्य की श्रृंखला में आ जायेंगे।

7. नई पीढ़ी के युवा कलाकारों को कल्ला जी यही संदेश देना चाहते हैं कि जिस भी कला को युवा कलाकार अपनायें उस कला के प्रति अपने आपको पूर्ण रूप से समर्पित कर दें क्योंकि किसी भी कला को सीखने के लिए नियमित अभ्यास, अनुशासन एवम् गुरू के प्रति श्रद्धा व ईमानदारी का भाव होना बहुत जरूरी है तभी तो कला में आप नए-नए प्रयोग व विविध आयाम स्थापित कर सकेंगे।

\section{निष्कर्ष}

लोक कला के संदर्भ में नृत्य निर्देशक श्री हरिदत्त कल्ला जी आपका मानना है कि लोक कला एक ऐसी कला है जिस पर किसी प्रकार का कोई बंधन नहीं होता। यह एक स्वतंत्र अभिव्यक्ति है। लोक कलाओं के संरक्षण तथा संवर्द्धन हेतु भारत सरकार ने सांस्कृतिक सांस्कृतिक केन्द्रों के माध्यम से, लोक कलाओं को उजागर करने, प्रोत्साहित करने का काफी कार्य किया है और कर रही है। समय बदलता जा रहा है वे लोक कलाकार जो अपनी स्वतंत्र अभिव्यक्ति को उजागर करते थे वे अब पूर्ण रूप से व्यवसायिक हो गए हैं और साथ ही अपनी एक दूसरे की 'कॉपी' करने लगे हैं जिसके कारण इन लोगों की मूल प्रवृति भी परम्पराओं के अनुसार विलुप्त होती जा रही है। लोक कलाओं में नवीनीकरण जरूरी है अन्यथा ये कलाएँ एक जगह रहकर सड़ जायेंगी। इस नवीनीकरण को आत्मसात् करने के लिए परम्पराओं को ध्यान में रखते हुए नवीनीकरण करना चाहिए। इन कलाओं का संरक्षण, कलाकारों को रोजगार देकर, इन कलाओं के वृतचित्र बनाकर एवम् इन विधाओं के कलाकारों की मंचीय प्रस्तुति करने के अवसर ज्यादा प्रदान करके किया जा सकता है। युवा कलाकार, कला के प्रति अपने आपको पूर्ण रूप से समर्पित कर दें तभी लोक कलाएं जीवित रह सकती हैं।

संदर्भ

नृत्य निर्देशक श्री हरिदत्त कल्ला जी से साक्षात्कार द्वारा प्राप्त। 